\title{
SEARCHING FOR CRITICAL CONDITIONS DURING LIFEBOAT LAUNCHING - SIMULATIONS
}

\author{
Czesław Dymarski \\ Paweł Dymarski \\ Aleksander Kniat \\ Gdansk University of Technology, Poland
}

\begin{abstract}
The article describes numerical simulations of the process of lifeboat launching at the ship's side. The research aimed at finding the values of ship motion parameters which appear to be most dangerous for people in the lowered lifeboat due to the generated accelerations. The simplified model of ship hull motion adopted at this research stage bases on a superposition of harmonic motions with given amplitudes and periods in six degrees of freedom. The range of the amplitude of motion for each degree of freedom corresponds approximately to that of possible motion of the PANAMAX type ship on the Baltic sea. In total, 120960 cases of ship hull motion were examined.
\end{abstract}

Keywords: lifeboat launching, numerical simulations, kinematics

\section{INTRODUCTION}

The aim to ensure the best possible safety of navigation for the crew and passengers on seagoing vessels has always been an important aspect for ship designers and owners. However, until the Titanic disaster, no consolidated requirements concerning lifesaving appliances and devices had been formulated for ship designers. Only after this tragedy the need for such requirements was recognised, which resulted in working out the SOLAS Convention (part III) and, based on this Convention, certain regulations adopted by classification societies. With time, as the number of vessels in operation increased and their design solutions and material technology developed, the level of requirements for both the lifesaving equipment, and the devices used for launching it on and lifting from water has gradually increased, which was reflected in introducing subsequent amendments, concerning, among other aspects, increased safety of evacuation in rough sea conditions. For instance, Ref. [13] describes a modern procedure of material property testing, while Refs. [5] and [8] publish results of calculations performed using the Finite Element Method (FEM).

The safety requirements which are currently in force are laid down in the International Life Saving Appliance
Code (LSA Code). This code has been brought into force in accordance with the amendments to the SOLAS Convention adopted by the Maritime Safety Committee (MSC) at its 66-th session in June 1996: - Resolution MSC.47(66) and Resolution MSC.48(66).

An essential requirement here is ensuring safe motion of the lifesaving device, a life raft or lifeboat for instance, over the ship's side and launching it on water, under unfavourable conditions of trim of up to $10^{\circ}$ and list of up to $20^{\circ}$, either way, using the gravity force or the collected energy, irrespective of the energy sources on the ship:

a) when the boat/raft is loaded with the full number of people provided for it, and

b) when only crew in on its deck.

Only for the life raft, moving it over the ship's side with the aid of the manual drive is allowed. The principles of design and use of these devices are described in [15].

The present article discusses the kinematics of the lifeboat during its launching. Like in [10], substituting expensive field tests by numerical simulations the authors aim to identify most dangerous conditions for the motion of the lifeboat with people at the ship's side. The results of these simulations will be used to eliminate dangerous scenarios of lifeboat launching and finding most favourable conditions for this 
action. Calculating the trajectory of motion, complemented by accelerations and speed of the lifeboat lowered on ropes, allows to learn better the effect of individual components of the designed device on parameters of its motion. This, in turn, will lead to the improvement of the designs of lifesaving devices, with respect to both their structure and applied materials, and subsequent softening of the effects of possible boat strokes against the ship's side. The results of the simulations performed for a large number of different lifesaving device types and launching scenarios will make the basis not only for finding the most favourable design solution and geometrical parameters of the device and its location, but also for selecting the optimal start time of launching in relation to the instantaneous ship position.

\section{PROCESS OF LIFEBOAT LAUNCHING FROM SHIP}

The increasing number of ships in operation and the abovementioned requirements concerning the lifesaving and rescue devices have stimulated intensive development of both design solutions, and drive and control systems of these devices.

At present, various types of davits are in common use. With respect to the way in which the boat or raft is moved over the ship's side, their designs can be divided into:

- level-luffing - sample davit of this type is shown in Fig. 1.

- luffing,

- travelling-luffing,

- travelling-telescope,

- round-bar,

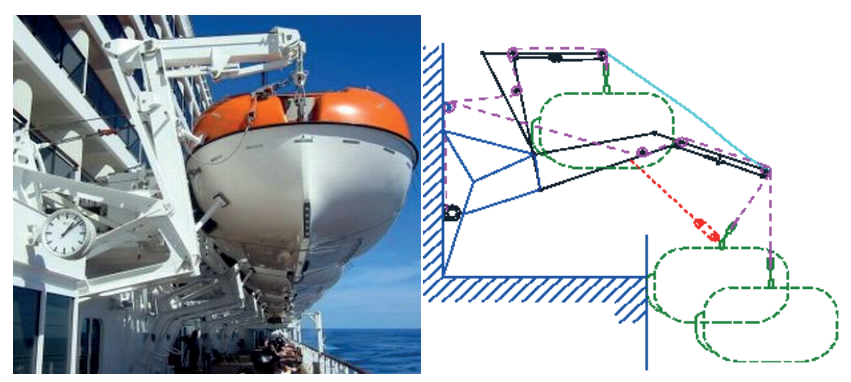

Fig. 1. Photo and kinematic scheme of the level-luffing davit in three characteristic positions: - cruising, - at ship's side when the people are directed from the evacuation deck to the boat, - during boat launching.

The system of davits with lifeboats is sometimes complemented by the Marine Evacuation System (MES), which usually consists of large rafts and, optionally, platforms. This solution is mainly used on new passenger ships taking large numbers of people. In the MES system, the people slide down, using special chutes, from the ship deck onto the platform or directly to the raft. Due to highly unpredictable behaviour of passengers, attempts are made to simulate the evacuation process, see [9] for instance, to be able to predict possible difficulties and problems.
A common feature of all devices in which the lifeboat is lowered on ropes is the similar procedure of evacuating people from the ship. This procedure includes the following stages:

- removing protections mounted for the time of voyage and moving the davit with the boat over the ship's side,

- lowering the boat on the ropes to the evacuation deck level and pulling the boat to the ship's side,

- preparing passages, directing people from the deck to the boat, locking safety belts, and closing the boat door,

- detaching the ropes which pressed the boat to the ship's side and, once the boat hangs free, releasing the rope winch brake to allow the boat to lower gravitationally at the speed stabilised by the centrifugal brake of the winch,

- when the boat nears the water, lifting the hook release lever to allow the hydrostatic release to act when the boat is on water. Its action will automatically release both hooks and disconnect the boat from the ropes, thus allowing it to sail away from the ship.

\section{CALCULATION MODEL USED IN SIMULATION}

The calculation model elaborated to simulate the process of boat launching consists of the following components, shown in a simplified form in Fig. 2:

a) ship hull - subjected to harmonic motions in all six degrees of freedom with respect to its centre of gravity,

b) davit arms - fixed to the permanent upper deck structure of the ship hull,

c) ropes - connecting the davit with the boat,

d) mechanism for running out the rope (rope winch with centrifugal brake and locking brake, and passive compensator),

e) lifeboat with fenders.

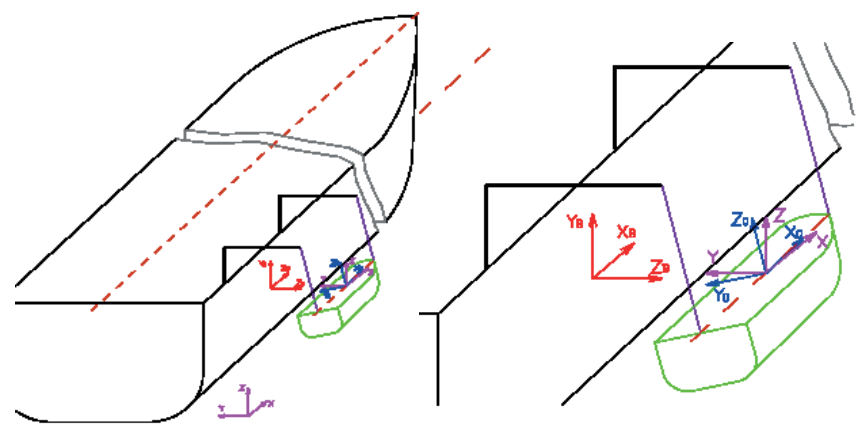

Fig.2. Simplified view of the model used in the simulation.

Relevant kinematic constraints were created for particular model components. The ship hull experiences harmonic motions in all degrees of freedom, thus defining the excitations in the remaining model components. The linear motions of the boat are described by Equations (2.1), while its angular motions are given by Equations (2.2). Both equation sets were assumed according to the literature [7]. 


$$
\begin{gathered}
m \ddot{x}_{c}=\sum_{i=1}^{k} F_{x i} \quad m \ddot{y}_{c}=\sum_{i=1}^{k} F_{y i} \quad m \ddot{z}_{c}=\sum_{i=1}^{k} F_{z i} \\
I_{x_{0}} \ddot{\varphi}_{x_{0}}-\left(J_{x_{0}}-J_{z_{0}}\right) \dot{\varphi}_{y_{0}} \dot{\varphi}_{z_{0}}=\sum_{i=1}^{k} M_{x_{0} i} \\
I_{y_{0}} \ddot{\varphi}_{y_{0}}-\left(J_{z_{0}}-J_{x_{0}}\right) \dot{\varphi}_{z_{0}} \dot{\varphi}_{x_{0}}=\sum_{i=1}^{k} M_{y_{0} i} \\
I_{z_{0}} \ddot{\varphi}_{z_{0}}-\left(J_{x_{0}}-J_{y_{0}}\right) \dot{\varphi}_{x_{0}} \dot{\varphi}_{y_{0}}=\sum_{i=1}^{k} M_{z_{0} i}
\end{gathered}
$$

where:

$x_{c}, y_{c}, z_{c}-$ coordinates of the boat's mass centre

$x_{0}, y_{o} z_{0} \quad-$ directions of principal axes of inertia of the boat

$\dot{\varphi}_{x_{0}}, \dot{\varphi}_{y_{0}}, \dot{\varphi}_{z_{0}}-$ instantaneous angular velocities of the boat rotating about its principal axes of inertia

$J_{x_{0}}, J_{y_{0}}, J_{z_{0}} \quad$ - principal moments of inertia of the boat

$F_{x_{0}}, F_{y_{0}}, F_{z_{0}} \quad$ - force vectors along principal axes of inertia

$M_{x_{0}}, M_{y_{0}}, M_{z_{0}}-$ vector moments of inertia in relation to principal axes of inertia

\section{SELECTING RANGES OF HULL MOTION PARAMETERS}

An important limitation for the performed calculations is the time of computation required to obtain final results. The above described calculation model was implemented in the form of a computer code, written in $\mathrm{C}++$ by dr. Paweł Dymarski and described in [2] and [3]. The code allows to simulate the entire process of boat lowering, from the time of boat hook release to boat setting on water and disconnecting from the ropes on which it was lowered. The time of computations for a single set of parameters defining the simulation conditions is equal to about 1.5 minute on a mid-class PC. That means that the computations for 121000 cases would require 181500 minutes, i.e. 3000 hours (or 126 days $=4.2$ months). Such a long computing time is inacceptable in practice.

That is why a decision was made to perform computation at a professional computer centre. For this purpose, the code was modified in such a way as to enable running it on a computing cluster available at the Academic Computer Centre (CI TASK) in Gdansk. The cluster comprises 32000 processors and allows to perform parallel computations. However, due to a large number of users, the real access to the cluster is limited. In the present case, about a thousand of parallel computations could be performed simultaneously.

The available data on sea waves in the Baltic sea water region have made the basis for selecting parameters for calculations. The selected parameter values are given in

\begin{tabular}{|c|c|c|c|c|c|}
\hline & & $\begin{array}{c}\text { Min } \\
\text { value }\end{array}$ & $\begin{array}{l}\text { Max } \\
\text { value }\end{array}$ & Step & $\begin{array}{l}\text { Number } \\
\text { of cases }\end{array}$ \\
\hline \multirow{3}{*}{ 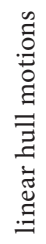 } & $\begin{array}{l}\text { amplitude with respect } \\
\text { to } Z \text {-axis }\end{array}$ & $0 \mathrm{~m}$ & $6.0 \mathrm{~m}$ & $0.3 \mathrm{~m}$ & 21 \\
\hline & $\begin{array}{l}\text { amplitude with respect } \\
\text { to Y-axis }\end{array}$ & $0 \mathrm{~m}$ & $0.5 \mathrm{~m}$ & $0.5 \mathrm{~m}$ & 2 \\
\hline & $\begin{array}{l}\text { amplitude with respect } \\
\text { to } \mathrm{X} \text {-axis }\end{array}$ & $0 \mathrm{~m}$ & $0.5 \mathrm{~m}$ & $0.5 \mathrm{~m}$ & 2 \\
\hline \multirow{4}{*}{ 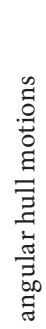 } & $\begin{array}{l}\text { amplitude with respect } \\
\text { to } Z \text {-axis }\end{array}$ & $0^{\circ}$ & $4^{\circ}$ & $2^{\circ}$ & 3 \\
\hline & $\begin{array}{l}\text { amplitude with respect } \\
\text { to Y-axis }\end{array}$ & $0^{\circ}$ & $8^{\circ}$ & $2^{\circ}$ & 5 \\
\hline & $\begin{array}{l}\text { amplitude with respect } \\
\text { to X-axis }\end{array}$ & $2^{\circ}$ & $16^{\circ}$ & $2^{\circ}$ & 8 \\
\hline & $\begin{array}{l}\text { phase with respect to } \\
\mathrm{X} \text {-axis }\end{array}$ & $0^{\circ}$ & $330^{\circ}$ & $30^{\circ}$ & 12 \\
\hline \multicolumn{5}{|c|}{ Total number of cases: } & 120960 \\
\hline
\end{tabular}
Table 1 . The periods for particular motions were assumed based on the wave data published in [4] and [11].
Table 1. Ship hull motion parameter values assumed in the simulation.

The maximal wave height recorded on the Baltic sea is about $15 \mathrm{~m}$, but this extreme value occurs very rarely. The research performed at the PAS Institute of Hydroengineering, Gdansk, Poland, and published in [11] indicates that even during heavy storms the wave height rarely exceeds $6 \mathrm{~m}$. This assessment is also confirmed by global wave statistics presented in [4]. Moreover, the design practice recommends to assume the so-called "significant" wave height, which is even smaller and acc. to [1] does not exceed $4,3 \mathrm{~m}$ on the Baltic sea. Having taken all this into consideration, it was assumed that the ship hull heaving, damped with respect to sea waves, does not exceed $6 \mathrm{~m}$.

The remaining parameters of motion were selected based on classification regulations. Ref. [16] in Chapter 10 Item 1.1 clearly states that each device used for launching and lifting a lifeboat should be designed in such a way as to ensure safe operation under conditions of ship trim of up to $10^{\circ}$ and list of up to $20^{\circ}$, either way. The regulations do not say whether these limits are static or dynamic in nature. In the engineering practice they are considered static, but in the present case they were assumed as dynamic conditions, therefore their ranges were slightly decreased: list to $16^{\circ}$, and trim to $8^{\circ}$. Due to insufficient data on phenomena taking place during lifeboat launching and the fact that the present research was mainly focused on this process, a relatively simple model of waves and effects of their activity was used, compared to that described in [6], for instance.

The selected values of ship hull motion amplitudes in particular degrees of freedom, complemented by relevant phase shifts in the angular motion about the $\mathrm{X}$-axis, resulted in a total number of 120960 examined cases. The adopted parameters were considered most representative and best describing possible and permissible variants of ship hull motion in this water region. For each case, a simulation was performed using the lifeboat of $8.8 \mathrm{~m}$ in length and having the mass of $15550 \mathrm{~kg}$. 


\section{RESULTS OF SIMULATION}

Parallel computations performed at CI TASK allowed to collect results for all 120960 cases after about two hours. For each case, a check was made whether or not the lowered boat struck against the ship's side and what the maximum accelerations acting on the lowered boat were.

All cases in which there was no boat stroke against the ship's side were considered safe. The total number of such cases amounted to 4470 . The maximal accelerations recorded in these cases were much lower than when the stroke took place.

Table 2 collects rates of incidence of particular acceleration values obtained from the calculations. Figure 3 presents the same data in graphical form. They reveal that in 108210 cases, which is more than $89 \%$ of all examined cases, the accelerations did not exceed $3,5 \mathrm{~g}$.
Table 3. Ship hull motion parameters for which the highest value of linear motion acceleration acting on the launched boat was recorded.

\begin{tabular}{|c|c|c|c|}
\hline & & amplitude & period \\
\hline \multirow{3}{*}{ 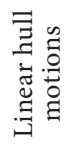 } & Z-axis & $5.7 \mathrm{~m}$ & $8.4 \mathrm{~s}$ \\
\hline & Y-axis & $0.5 \mathrm{~m}$ & $12.0 \mathrm{~s}$ \\
\hline & $\mathrm{X}$-axis & $0.0 \mathrm{~m}$ & - \\
\hline \multirow{4}{*}{ 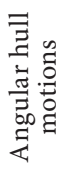 } & $\mathrm{Z}$-axis & $4.0^{\circ}$ & $12.0 \mathrm{~s}$ \\
\hline & Y-axis & $0.0^{\circ}$ & - \\
\hline & $\mathrm{X}$-axis & $12.0^{\circ}$ & $7.3 \mathrm{~s}$ \\
\hline & phase with respect to $\mathrm{X}$-axis & \multicolumn{2}{|c|}{$30^{\circ}$} \\
\hline
\end{tabular}

The recorded maximal acceleration took place when the lowered boat struck against the ship's side. Figures 4 and 5 show, respectively, the time-histories of changes of the lifeboat's centre of gravity when the boat was lowered under the above critical conditions, and linear acceleration changes for the same case.

Table 2. Rates of incidence of particular acceleration values.

\begin{tabular}{|c|c|c|c|c|c|c|c|c|c|c|c|c|c|c|c|c|c|c|c|c|}
\hline 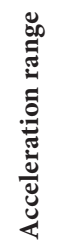 & $\stackrel{\infty}{-1}$ & 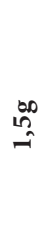 & 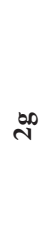 & $\begin{array}{l}\text { م) } \\
\hat{n} \\
\hat{n}\end{array}$ & "ా & 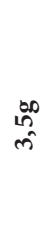 & $\stackrel{\infty}{+\infty}$ & $\begin{array}{l}b 00 \\
\stackrel{1}{10} \\
+4\end{array}$ & ది & $\begin{array}{l}b 0 \\
10 \\
\text { in }\end{array}$ & 80 & 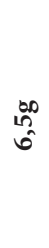 & 200 & 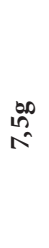 & $\infty$ & $\begin{array}{l}00 \\
100 \\
\infty \\
\infty\end{array}$ & 20 & $\begin{array}{l}100 \\
{ }^{n} \\
\sigma^{2}\end{array}$ & 0 & $\begin{array}{l}+\infty \\
\hat{0} \\
0\end{array}$ \\
\hline
\end{tabular}

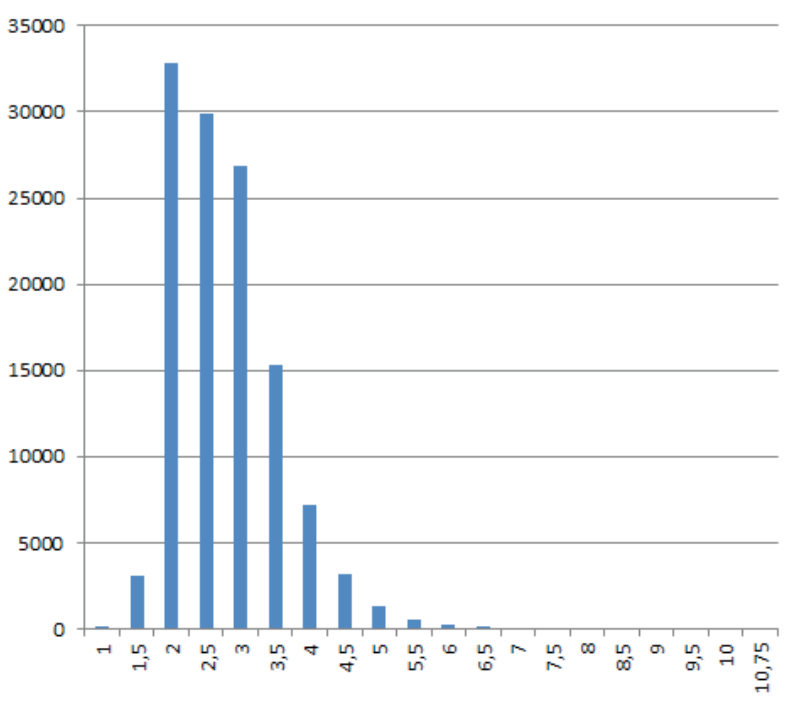

Fig. 3. Incidence rate diagram for particular acceleration values.

The maximal acceleration, amounting to: $103.55 \mathrm{~m} / \mathrm{s}^{2}$ (components: $\mathrm{X}=-10,65 ; \mathrm{Y}=-102.06 ; \mathrm{Z}=13.92$ ) was recorded after 17.8 seconds from the beginning of boat lowering, for ship parameters given in Table 3 .

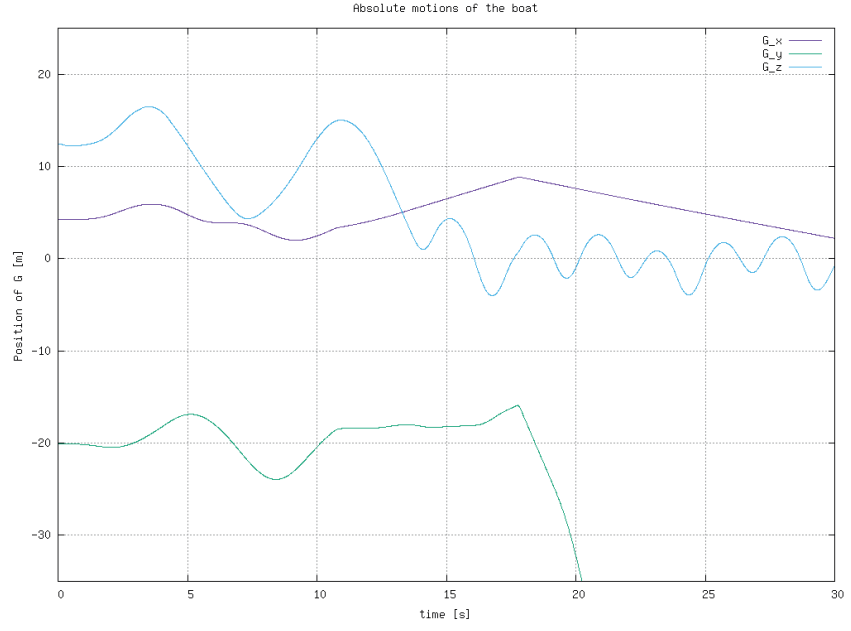

Fig. 4. Time-history of centre of gravity position changes for the lifeboat launched under critical conditions. 


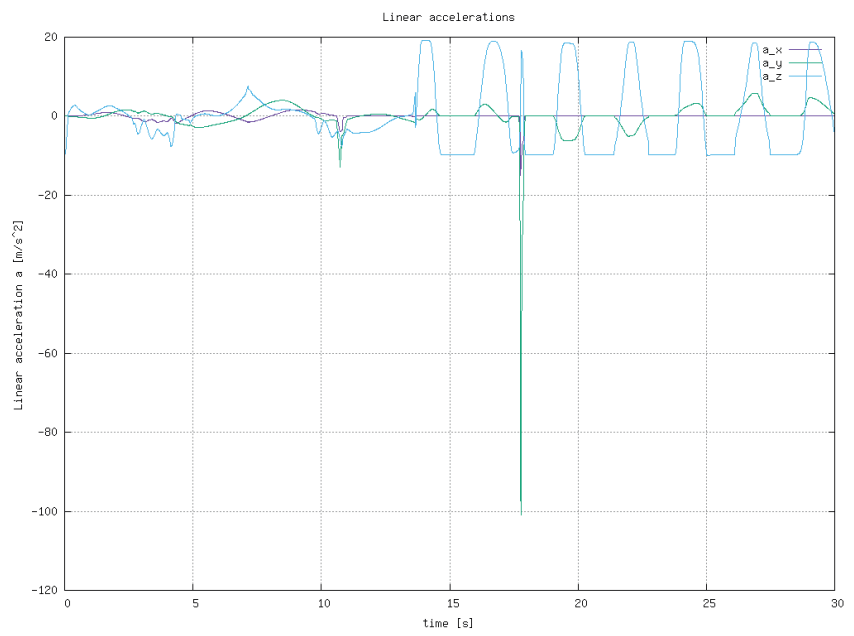

Fig. 5. Time-history of linear accelerations acting on the boat launched under critical conditions.

A distinctive peak in the green curve in Fig. 4, between 15 and 20 second, illustrates the lifeboat's stroke against the ship's side. A negative peak, observed for the same time in the green line representing the Y-component of acceleration (perpendicular to the ship's side) in Fig. 5, is even more prominent.

\section{CONCLUSIONS}

The case selected from among all 120960 cases in the previous Chapter is the extreme case. The recorded linear acceleration amounting to $103.55 \mathrm{~m} / \mathrm{s}^{2}$, which was recorded during lifeboat's stroke against the ship's side, is unacceptable for people in the boat and is likely to destroy the boat itself. It turns out that for the same ship hull motion amplitudes, but different phase shifts, the recorded accelerations can be lower, as seen in Table 4.

Table 4. Maximal linear accelerations for the same amplitudes of ship hull motion and different phase shifts with respect to the $X$-axis.
That is why of great importance is the selection of the start time for lifeboat launching. Minimising the boat rocking in the beginning phase of lowering to protect the boat against kinetic energy gaining is very important, as this kinetic energy is extremely dangerous when the boast strikes against the ship hull. An attempt to evaluate possible effects of such strokes is made in [12].

The lifeboat launching process is affected by numerous factors, including flexibility of particular structural elements of davits, characteristics of their mechanisms, as well as the ship position and instantaneous motion parameters at the time when the boat launching is started. For instance, such simple elements as fenders can have a significant impact on the values of the accelerations recorded when the boat strikes against the ship hull. The boat fender which was taken into account in the present calculations had a linear characteristic, i.e. its deflection was proportional to the applied force. Further research oriented on developing a new characteristic of the fender would undoubtedly lead to changes in the course of motion of the lifeboat bouncing off the ship's side and could considerably reduce the level of accelerations recorded in this motion. However, this issue is very wide and worth analysing in a separate article.

The calculation model presented in this article allows to perform a detailed analysis of a single case of lifeboat launching from ship at given parameters. Transferring the calculations to the cluster and performing them in parallel have provided opportunities for effective analysis of a large number of cases. Such a two-stage analysis allowed first to identify most dangerous cases based on the assumed limits, the critical acceleration value for instance, and then to analyse in detail possible causes of their appearance. This identification and analysis will make it possible to introduce structural and functional changes to the lifeboat launching system, or at least to introduce a procedure which will force a more favourable course of events during boat lowering. However, a detailed study of possible solutions intended to improve the lifeboat launching goes beyond the scope of this article and will be discussed in further publications.

\begin{tabular}{|c|c|c|c|c|c|c|c|c|c|c|c|}
\hline \multirow{2}{*}{ Item } & \multicolumn{3}{|c|}{ Linear motions $[\mathrm{m}]$} & \multicolumn{4}{|c|}{ Angular motions $\left[^{\circ}\right]$} & \multicolumn{4}{|c|}{ Linear acceleration $\left[\mathrm{m} / \mathrm{s}^{2}\right]$} \\
\hline & amp. Z & amp. Y & amp. $X$ & amp. Z & amp. Y & amp. $X$ & $\begin{array}{c}\text { phase } \\
\text { X }\end{array}$ & $\mathbf{x}$ & $\mathbf{Y}$ & $\mathrm{Z}$ & Resultant \\
\hline 1. & \multirow{12}{*}{$\begin{array}{l}R \\
\text { in }\end{array}$} & \multirow{12}{*}{$\stackrel{\substack{n \\
0}}{0}$} & \multirow{12}{*}{$\stackrel{8}{\circ}$} & \multirow{12}{*}{$\stackrel{\circ}{\circ}$} & \multirow{12}{*}{$\ddot{0}$} & \multirow{12}{*}{ 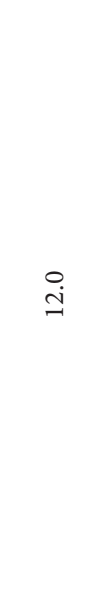 } & 0 & -3.81 & -19.33 & 4.26 & 20.19 \\
\hline 2. & & & & & & & 30 & -10.65 & -102.06 & 13.92 & 103.55 \\
\hline 3. & & & & & & & 60 & -1.75 & 1.88 & 19.36 & 19.53 \\
\hline 4. & & & & & & & 90 & 1.74 & 4.32 & 23.65 & 24.11 \\
\hline 5. & & & & & & & 120 & 4.15 & 8.59 & 20.31 & 22.44 \\
\hline 6. & & & & & & & 150 & -5.20 & -4.54 & 22.08 & 23.13 \\
\hline 7. & & & & & & & 180 & 6.81 & 6.02 & 25.53 & 27.10 \\
\hline 8. & & & & & & & 210 & -3.18 & -29.49 & -9.10 & 31.02 \\
\hline 9. & & & & & & & 240 & -0.56 & -19.22 & 15.13 & 24.47 \\
\hline 10. & & & & & & & 270 & 8.39 & -37.93 & 10.94 & 40.36 \\
\hline 11. & & & & & & & 300 & 8.73 & -36.85 & 1.90 & 37.92 \\
\hline 12. & & & & & & & 330 & 0.99 & -18.83 & -4.60 & 19.41 \\
\hline
\end{tabular}




\section{BIBLIOGRAPHY}

1. Dudziak J., The theory of the ship (in Polish). Wydawnictwo Morskie, Gdańsk 1988.

2. Dymarski P. Dymarski Cz., COMPUTATIONAL MODEL FOR SIMULATION OF LIFEBOAT MOTIONS DURING ITS LAUNCHING FROM SHIP IN ROUGH SEAS, Polish Maritime Research Vol. 19 No. 3(75), 2012.

3. Dymarski P., Dymarski Cz., Safecrafts GUT_WP2_D2.3 - Report, 2006-04-07 Gdańsk.

4. Hogben, N., Da Cunha, N. M. C. and Oliver, G. F., GLOBAL WAVE STATISTICS. Compiled and edited by British Maritime Technology, Unwin Brothers, UK, 1986.

5. Iwicki P., Tejchman A., Chróścielewski J., DYNAMIC FE SIMULATIONS OF BUCKLING PROCESS IN THINWALLED CYLINDRICAL METAL SILOS, Thin-walled structures. Vol. 84 (2014), pp.344-359.

6. Kozicki J., Niedostatkiewicz M., Tejchman A., Muhlhaus H., DISCRETE MODELLING RESULTS OF A DIRECT SHEAR TEST FOR GRANULAR MATERIALS VERSUS FE RESULTS. Granular Matter, Vol. 15, iss. 5 (2013), pp.607-627.

7. Veic D., Kraskowski M., Bugalski T., BOTTOM FIXED SUBSTRUCTURE ANALYSIS, MODEL TESTING AND DESIGN FOR HARSH ENVIRONMENT. Ostachowicz W. et al. (eds.), MARE-WINT, Chapter 13, DOI 10.1007/978-3-319-39095-6_13.

8. Kruszewski J., Ostachowicz W., Wittbrodt E., General Mechanics (in Polish), Gdansk University of Technology, Gdansk 1993.

9. Kujawa M., Szymczak C., NUMERICAL AND EXPERIMENTAL INVESTIGATION OF ROTATIONAL STIFFNESS OF ZED-PURLINS CONNECTION WITH SANDWICH PANELS, Thin-walled structures, Vol. 75, (2014), pp.43-52.

10. Magluta C., Roitman N., Batista R.C. DYNAMIC BEHAVIOUR ANALYSIS OF A LIFEBOAT SYSTEM UNDER SIMULATED ACCIDENTS, Mechanical Systems and Signal Processing, Volume 10, Issue 6, November 1996, Pages 763-774.

11. Morch H. J., Peric M., Schreck E., Moctar O., Zorn T., SIMULATION OF FLOW AND MOTION OF LIFEBOATS, ASME 2009 28th International Conference on Ocean, Offshore and Arctic Engineering, Volume 5: Polar and Arctic Sciences and Technology; CFD and VIV, Paper No. OMAE2009-79608, pp. 595-605; 11 pages, doi:10.1115/
OMAE2009-79608, Honolulu, Hawaii, USA, May 31June 5, 2009.

12. Paplińska-Swerpel B., Paprota M., Przewłócki J., Sulisz W., ANALYSES OF WAVE RECORDS FROM THE SOUTHERN BALTIC SEA WITH THE EMPHASES ON LARGE WAVE EVENTS. Dynamics of coastal waters and their modelling: Proceedings of the 9th German Polish Seminar. Ed. J. Sündermann, Hamburg: IFM, GKSS Printing Office, 2005, Berichte aus dem ZMK, B 49, s. 5-16.

13. Raman-Nair W., Chin S.N., ESTIMATION OF IMPACT FORCES BETWEEN SMALL BODIES IN WAVES, Ocean Engineering, Volume 46, June 2012, Pages 46-51.

14. Rucka M., Wilde K., EXPERIMENTAL STUDY ON ULTRASONIC MONITORING OF SPLITTING FAILURE IN REINFORCED CONCRETE. Journal of nondestructive evaluation. Vol. 32, Issue 4 (2013), pp.372-383.

15. Söding H., FLOW COMPUTATIONS FOR SHIP SAFETY PROBLEMS, Ocean Engineering, Volume 29, Issue 7, June 2002, Pages 721-738.

16. Taylor D.A., INTRODUCTION TO MARINE ENGINEERING (Second Edition), Chapter 10 - Deck machinery and hull equipment, 1996, Pages 180-199.

17. Non-classification regulations concerning the equipment of sea-going vessels (in Polish), Polish Ship Register, Gdańsk, 1990.

\section{CONTACT WITH THE AUTHORS}

\author{
Czesław Dymarski \\ Paweł Dymarski \\ Aleksander Kniat \\ Gdansk University of Technology \\ Faculty of Ocean Engineering and Ship Technology \\ 11/12 Narutowicza St. \\ 80 - 233 Gdańsk \\ Poland
}

